\title{
Research on Strategy of Improving substantial Results of Sports Biochemistry Course
}

\author{
QI'E Zhu \\ College of Physical Education \\ Hubei University of Science and Technology \\ Xianning,Hubei,China
}

\begin{abstract}
Pointed out the objective reality of current situation of sports biochemistry course lagging subject development,it is bad for training reserve sports biochemistry course substantial results is the key to resolve this problem,proposed three strategies:exquisite choice and careful interpretation for substantial results and promoting development through research.
\end{abstract}

Keywords- sports biochemintry;course;substantial results; strategy

\section{INTRODUCTION}

Sports biochemistry belongs to the group of sports biological courses, is a compulsory course for students majoring in sports human science, physical education, sports training and traditional sports in Colleges and universities. This course researches the change rule of sports human from the molecular level, and is a edge science generated by mutual penetration, cross between the natural science and the humanities and social science[1]. Although the requirements of different professional direction on the course is not same, but because of the course plays a key role for the promotion of sports training and scientific national fitness, therefore, to master the sports biochemistry knowledge and skills systematically, meet the course requirements is the basic learning tasks for students mentioned above.However, the current situation is that the students generally reflect that this course is abstruse, and difficult to learn ,so the teaching effect is not optimistic[2,3,4], which is not extremely consistent with the status of sports biochemistry. Many sports biochemistry first-line teachers put forward their views on teaching methods. Based on the summary and development of peer opinions, combining with the nature of sports biochemistry course, this article thinks that highlight the effectiveness of this course is the root of the problem, and proposes the corresponding strategy, hope to be able to offer practical help to this course.

\section{THE DESCRIPTION AND PRESENT SITUATION ANALYSIS OF THE SPORTS BIOCHEMISTRY COURSE}

\section{A. the course description}

Sports biochemistry is the result of mutual combination and development between the sports science and biological chemistry.From the molecular level, it is a scientific and strong applied course that researches the body's chemical composition,metabolic changes,energy generation, the change and development of exercised ability.In this course,the main task is to reveal the nature of human sports change,monitor and evaluate function of human sports state,and scientifically guide physical exercise and exercise training, and the teaching goal is to enable students to master the principle and method of physical exercise and exercise training,trains the student's ability to discover , analyze and solve problems through scientific experiments.So to say,sports biochemistry is an important course which can construct the basic theory and skills of sports biological science, and to cultivate students' comprehensive quality.

\section{B. The current situation analysis of disciplines and the} course

Sports biochemistry is very young and developing rapidly discipline, with the continuous increase of the competitive sports and mass scientific fitness level,biochemical methods and research results have been applied to these fields, and achieved satisfactory results.For example, the research of physical exercise methods to prevent and control some chronic diseases such as diabetes,obesity and cardiovascular disease. In the $21 \mathrm{st}$ century,people will pay more attention to their health level and quality of life, and it is one of the exercise biochemistry's main task to fully explore the relationship between exercise and these chronic diseases and prevention mechanism,to provide people with scientific physical treatment method[5], and develop the corresponding exercise prescription for different individuals.Sports biochemistry is the basis for the sports nutrition, from the perspective of biochemistry, nutrition is "individual level of biochemistry" based on metabolism[6],plays an important role in promoting fatigue recovery,improving the sports ability and anti-doping research.It is visible that the status and the contribution of sports biochemistry in sports biological science is without a doubt, and under the impetus of molecular biology and other life science and technology rapid development,sports biochemistry will gradually show its powerful academic value and vitality.

However, it is not optimistic that the prosperity of the subject is not matching to the teaching situation of this course.Enough as the teaching unit pays attention to the course, the students generally reflect sports biochemistry is so difficult, not easy to master, and teachers are also not satisfied with current teaching effect[2,3,7,8]. This worrying teaching status would severely hinder the healthy and longterm development of subject, and make professional values 
frustrate. while the cause of this situation are various, such as teaching methods, teaching management, teaching material construction, etc. To solve the problem should grasp the principal contradiction, while improving the efficiency of the sports biochemistry course from all aspects is a key link in solving the problem of course and laying a solid foundation in the process of subject development.

\section{THE ANALYSIS OF THE STRATEGY TO IMPROVE SPORTS BIOCHEMISTRY COURSE EFFICIENCY}

\section{A. fine select and give a detailed lecture for the important content}

Generally speaking, sports biochemistry should be taught three aspects,including the material basis for the human sports body and energy metabolism,exercise training biochemistry and physical exercise biochemistry, but due to the teaching hours restrictions, we can only choose one of which is relatively important in the practical teaching content and have to delete a portion of the content.The body's aerobic and anaerobic metabolism system" and "the relationship and regulation of metabolism " is the basic theory and the core knowledge of sports biochemistry, which should be treated as the focus of the course content,and penetrate in teaching method. Many peers put forward different views on the teaching method of this course,such as "Research teaching"[9], "Inquiry Teaching"[4], "Problem centered teaching", and these methods are worthy of recognition in enriching teaching means and the role of improving teaching quality, which reflects the students'dominant position in the teaching activities, and takes care of the students' interests, motivate the enthusiasm to learn. However,all methods and means is in order to achieve the teaching goal.For the basic theory and the core knowledge of the subjects, its teaching goal should be mastered on the basis of understanding. Because of exercise biochemistry study content is really micro and thorough,therefore,to make students master solid,only considering the teaching means and the students'enthusiasm is not enough.Basic theory of the sports biochemistry has the certain difficulty at the beginning stage in the course, so if teaching takes the student as the main body in the condition of not qualified, it's easy to make students have the fear emotions and the whole course teaching effect will be affected. In the teaching of core knowledge,we must fully play the leading role of teachers, and in the teaching process through the exercises, discussions, case analysis,etc,to help students understand and grasp. Core knowledge intensively grasped with corresponding sports knowledge, is the essential condition in the subsequent courses to carry out the students as the body, and other forms of teaching, and is also the premise that students can apply what they have learned theoretical knowledge to explain sports phenominon,and solve practical problems. Only do this,can let students feel the course useful and effective, and also make part of the student preparation for a higher level to carry out study and research in the future.

\section{B. replace the experimental teaching with practice}

The current sports biochemistry course includes theoretical teaching and experimental teaching.There are more fundamental,confirmatory experiments in its teaching,such as determination of blood lactate and blood urea,urinary protein, etc, with the continuous development of the teaching thought and the gradually thorough to understanding curriculum, these experiments were almost changed to the state of motion. from the evidence of literature reports[10], some colleges and universities also opened a comprehensive design experiment, which is very useful to improve the students' comprehensive application ability and consolidate of knowledge system.

However,experiment is carried out in the laboratory environment,although sports biochemistry is a subject that should focus on experimental technology, but the relatively closed teaching environment differ considerably from the application object,as for experimental technology and operation, has been involved in the previous courses, the key is the cultivation of application ability and reasonable explanation of the results.Sports biochemistry serves for training and national fitness, and most of students will engage in work related physical education and fitness guidance after graduation,so a similar learning environment should be created. In its teaching,replacing experimental teaching with practice is feasible and necessary.In practice,you can enable students to apply theoretical knowledge of sports biochemistry to evaluate a quality of PE lesson's exercises, or you can apply what you have learned to develop a training lesson plans and test training results or evaluate an object for which specific situations in developing training programme as well as.By means of this practice, it can fully motivate the spirit of students ' autonomous learning, create the actual work, also enable students to realize a sense of achievement and accomplishment of the useful learning to apply.This is the full embodiment of course effectiveness, and also plays a subtle role in guiding students to commit to the discipline of research.

\section{To show utility and promote development through scientific research}

On one hand,the teachers should lead the students who conform to the conditions and have will to carry out scientific research activities, these activities should not be asked for innovation and supper difficulty excessively,could start with phenomenon which students are interested in,or the questions which the students are hard to answer,through these activites, not only can make students understand the process of scientific research,but also illustrate the course utility via experimental result powerfully.On the other hand,teacher should explore in teaching and scientific research strenuously,pursui constantly,enhance acknowledge ability and teaching level,explain the new discovery and trend to the students, only in this way, a virtuous circle of excellent teaching,clear learning,willing exploration are fulfilled.Thus,sports biochemistry can show its practical utility and show the vigorous vatility. 


\section{CONCLUSION}

Sports biochemistry is playing a very important role in promoting scientific of athletic training and national fitness, the improvement of curriculum utility is the key part in showing the value of discipline and lasting and enhancing discipline vitality.to choose carefully and explain detailed for important content, to develop practice link and scientific research activities are realistic methods which can demonstrate and promote the effectiveness of the course.

\section{INTRODUCTION OF AUTHORS}

College of Physical Education, Hubei University of Science and Technology,

QI E Zhu,13098357915,xian ning city,xian an district,yong an road 2\#,Hu Bei province,437005,Sports Science of Human Body

\section{REFERENCES}

[1] MIN HAO Xie,LIN WEN Tao,WEI QUAN Feng Editor in chief.Sports biochemestry[M].BeiJing: People Sports Press,2008:5

[2] YA LI Xu.Preliminary Exploration on the Teaching Reform of Sports Biochemistry under Scientific Development Outlook[J].Science and Technology Innovation Herald ,2011,(19):154-155, 157
[3] ZHI YUN Ma. Preliminary Exploration on the Teaching of Sports Biochemistry for Undergraduate Majoring in Physical Education[J].Chapter,2012,(22)188

[4] QUN Yu,XI QUAN Weng,LI PING Wang.Implementation of Inquiry Teaching of Sports Biochemistry [J].Journal of An Shun Institute, 2012,14(6):71-74

[5] LIAN SHI Feng.Research Outlook of Sports Physiology and Sports Biochemistry in 21st Century[J].China Sports Science and Technology,2002,38(1):14-15, 22

[6] WEI QUAN Feng,MEI YUN Feng,etc.Some Problems in Sports Biochemistry and Sports Nutrition recently-Development of Sports Biochemistry Four[J]. Journal of BeiJing University of Physical Education,2001,24(1):64-68

[7] Xing Zhang. Preliminary Exploration on the Teaching of Sports Biochemistry Majoring in Physical Education[J].Science and Technology Innovation Herald,2009,(20):195

[8]SEN LIN Lu.Application of Appreciation Education in Sports Biochemistry Teaching [J].Vocational Education Forum,2012,(35): 26 27

[9]WEN Guo,YI ZHU Huang,etc. Preliminary Exploration of Research Teaching of Sports Biochemistry under Internet Enviroment[J].Journal of PE Institute Shan Xi Normal University,2010,25(1):82-84

[10]QUN Yu,XI QUAN Weng,LI PING Wang.Experimental Teaching of Sports Biochemistry and Cultivation of innovative Talents[J].Journal of An Shun Institute,2010,12(4):94-96 